\title{
Retinal blood flow alterations associated with scleral buckling and encircling procedures
}

\author{
Hironobu Ogasawara, Gilbert T Feke, Akitoshi Yoshida, Michael T Milbocker, John J Weiter, \\ J Wallace McMeel
}

\begin{abstract}
The bidirectional laser Doppler technique and monochromatic photography were used to measure the absolute blood flow rate in the major temporal retinal arteries in seven patients following unilateral scleral buckling and encircling procedures, and in two patients before and after removal of scleral buckling elements. In the seven patients who had undergone uncomplicated scleral buckling procedures the arterial flow rates were on average $50 \%$ lower $(p=0.01)$ in the surgically treated eyes than in the contralateral eyes. Removal of scleral buckling elements in two patients produced increases of $73 \%$ and $44 \%$ in arterial blood flow rates.
\end{abstract}

Ocular circulatory abnormalities have been associated with the repair of retinal detachment by scleral buckling and encircling procedures. Postoperative complications such as anterior segment ${ }^{1-4}$ or posterior segment ischaemia, ${ }^{56}$ or choroidal detachment, ${ }^{78}$ following scleral buckling procedures while rare, are probably related to ocular circulatory abnormalities.

Experimentally it has been $\operatorname{shown}^{910}$ that choroidal blood flow in the rabbit eye is reduced following scleral buckling procedures which involved the placement of encircling bands. The blood flow reduction was related to the degree of constriction of the band, ' and when the encircling bands were removed the blood flow returned to normal. ${ }^{10}$ Clinically Dobbie ${ }^{11}$ found evidence for reduced choroidal blood flow in patients following scleral buckling procedures from his analysis of alterations of the ocular pulse wave.

In an initial study using the laser Doppler technique our group ${ }^{12}$ reported that the pulsatile characteristics of the retinal arterial blood flow measured in eyes that had undergone uncomplicated scleral buckling procedures were altered compared with measurements obtained in fellow eyes. In addition a relative increase in retinal arterial blood flow was measured in one eye following removal of scleral buckling elements.

Table 1 Patient characteristics and surgical procedures

\begin{tabular}{llllllll}
\hline Patient & $\begin{array}{l}\text { Age } \\
\text { (years) }\end{array}$ & Sex & $\begin{array}{l}\text { Eye } \\
\text { treated }\end{array}$ & $\begin{array}{l}\text { Postoperative } \\
\text { period } \\
\text { (months) }\end{array}$ & $\begin{array}{l}\text { Detachment } \\
\text { duration } \\
\text { (weeks) }\end{array}$ & $\begin{array}{l}\text { Implant } \\
\text { extent } \\
\text { (quadrants) }\end{array}$ & $\begin{array}{l}\text { Implant/ } \\
\text { band }\end{array}$ \\
\hline 1 & 27 & F & Left & 88 & $2 \cdot 0$ & $1 \cdot 5$ & $276 / 40$ \\
2 & 28 & F & Left & 13 & $1 \cdot 0$ & 2 & $279 / 40$ \\
3 & 35 & M & Left & 52 & $1 \cdot 0$ & 2 & $279 / 240$ \\
4 & 47 & M & Left & 24 & $3 \cdot 0$ & $1 \cdot 5$ & $276 / 40$ \\
5 & 31 & M & Left & 15 & $0 \cdot 3$ & 2 & $276 / 40$ \\
6 & 33 & F & Right & 60 & $8 \cdot 0$ & $2 \cdot 5$ & $276 / 40$ \\
7 & 20 & M & Right & 89 & $1 \cdot 0$ & $1 \cdot 5$ & $276 / 40$ \\
\hline
\end{tabular}

Postoperative period = elapsed time between surgery and laser Doppler measurements.
In the current study we used the newer bidirectional laser Doppler technique and monochromatic retinal photography to measure for the first time absolute retinal blood flow rates in seven patients who had undergone unilateral scleral buckling procedures for the repair of retinal detachment. Specifically we compared the blood flow rates measured in retinal arteries of surgically treated eyes with the flow rates measured in corresponding arteries in fellow eyes. In two additional patients who experienced complications after scleral buckling procedures absolute blood flow rates were measured in retinal arteries before and after removal of the buckling elements.

\section{Patients and methods}

Seven patients who had undergone uncomplicated unilateral scleral buckling and encircling procedures for quadrant or half-retinal rhegmatogenous retinal detachments were referred for laser Doppler measurements. Written informed consent was obtained from each patient. The entry criteria for the study were history of a unilateral scleral buckling procedure, no other known retinal vascular disease, visual acuity correctable to at least $20 / 70$, adequate pupillary dilatation, and clear media. Characteristics of these patients and details of the surgical procedures are summarised in Table 1. The patients ranging in age from 20 to 47 years (mean 32 years) were referred for retinal blood flow measurements 13 to 89 months (mean 49 months) postoperatively. Refractive error ranged from 0 to -6.00 dioptres. Visual acuity was $20 / 30$ or better in each eye. No other ocular or systemic disease was present. Duration of retinal detachment (mean 2.3 weeks) was estimated from the onset of symptoms described by the patients. In each case a no 276 or no 279 solid silicone intrascleral implant and a no 40 or no 240 encircling band were used in the buckling procedures. The extent of the intrascleral implant was 1.5 or 2.5 quadrants and was consistent with the size of the detachment. All patients were treated with diathermy in the bed of the scleral dissection. There were no ocular complications during surgery or postoperatively. In fellow eyes five patients had been treated with local cryotherapy around peripheral retinal holes. The other two patients had received no treatments in their fellow eyes.

Two additional patients were referred for retinal blood flow measurement before and after removal of scleral buckling elements. Written informed consent was also obtained from these patients. The first, a 38-year-old male, originally presented with a retinal detachment in his left 
eye. Ophthalmoscopic examination revealed a superotemporal quadrant retinal detachment with tears at the 11 o'clock position in the periphery. The right eye was normal. He underwent an uncomplicated scleral buckling procedure with cryotherapy around the tears. A no 276 solid silicone intrascleral implant was placed anti-clockwise from 1 o'clock to 80 'clock. Diathermy was applied throughout the scleral bed. Subretinal fluid was drained. No encircling band was used. Sixteen months later the retina remained attached, visual acuity was $20 / 20$, and intraocular pressure was $17 \mathrm{~mm} \mathrm{Hg}$. However slit-lamp examination revealed external redness over the buckle, a suture abscess, and extrusion of the implant. On the following day scleral buckling elements were removed without complications. Laser Doppler measurements were performed on the day before and 3 weeks following surgery.

The second, a 42-year-old male, originally presented with an inferonasal quadrant retinal detachment with a horseshoe tear at the 5 o'clock position in the right eye. Refractive error was -6.50 dioptres, visual acuity was $20 / 60$, and intraocular pressure was $32 \mathrm{~mm} \mathrm{Hg}$. Treatment for elevated intraocular pressure was initiated. He underwent cryotherapy around the tear and a scleral buckling procedure. A no 279 silicone intrascleral implant was placed clockwise from 3.30 to 5.30 and a no 40 encircling band was then placed around the globe. Diathermy and dirainage of subretinal fluid were not performed. Twenty nine months later a superonasal retinal detachment with a horseshoe tear at the 12.30 position was found. A second scleral buckling procedure, with cryotherapy around the new tear, was performed using a no 276 solid silicone intrascleral implant placed clockwise from 12.00 to 1.30 under the original encircling band. Eleven months after the second surgical repair ophthalmoscopic examination revealed transcleral intrusion of a bent encircling band at the 12 o'clock meridian. Thirty one months later the retina overlying the bent portion of the band was found to be eroded. In preparation for subsequent surgery the eroded region was surrounded by laser photocoagulation. Two months later the encircling band was cut and a $2 \mathrm{~mm}$ portion was removed without complications. Laser Doppler measurements were performed on the day before and 10 weeks following surgery.

\section{LASER DOPPLER TECHNIQUE FOR RETINAL BLOOD} FLOW MEASUREMENT

The principles of our application of the laser Doppler technique for measurement of blood velocity in retinal arteries have been described previously in detail. ${ }^{13}$ With our technique the instantaneous centreline red blood cell velocity is determined from the spectral analysis of Doppler-shifted light scattered simultaneously in two directions (the so-called bidirectional technique). Prior to the retinal blood flow measurements pupils were dilated with $1 \%$ tropicamide. Monochromatic $(575 \mathrm{~nm})$ fundus photographs were taken of each eye. Intraocular pressure was measured by applanation tonometry and brachial artery blood pressure was measured by sphygmomanometry.

During data acquisition patients were positioned before a slit-lamp apparatus equipped with a helium-neon laser light source $(\lambda=633 \mathrm{~nm})$ and detector assembly consisting of two photomultiplier tubes. The signals from the photomultiplier tubes were recorded simultaneously on two tracks of a Honeywell 5600C Recorder/Reproducer for approximately 1 minute at each measurement site. A pulse synchronous with the heart rate was recorded on a third track using a transducer attached to the patient's fingertip.

For data analysis a frequency tracking system was used to identify portions of the recorded photocurrent showing regular systolic-diastolic variations in the Doppler-shift frequency. These portions were recorded when the incident beam was well-centred on the retinal artery. Spectral analysis of the identified portions of the recorded photocurrent was carried out under computer control. A Hewlett-Packard HP 9816S instrumentation-controlling computer was interfaced with two Wavetek 5809 digital spectrum analysers. Pairs of Doppler-shift spectra were obtained throughout the cardiac cycle and displayed on two Electrohome video monitors. Each spectrum exhibited large fluctuations in spectral power up to a clearly measurable maximum frequency shift corresponding to the velocity of the red blood cells flowing at the centreline of the artery. The spectrum and the maximum frequency shift was then read out onto a Hewlett-Packard HP 7470A digital graphics plotter.

The time average of the centreline blood velocity during the cardiac cycle $(\bar{V})$ was determined using the previously established relationship ${ }^{13}$ :

$\bar{V}=V$ (diastole $)+k \quad[V($ systole $)-V($ diastole $)]$ where $k=0.48$ (SD $0 \cdot 04$ ). The blood flow rate was calculated as

Flow $=\bar{V} \times$ area $/ 2$

where area is the cross-sectional area of the retinal artery at the laser Doppler measurement site. ${ }^{1+}$ The area was calculated from the measured blood column diameter assuming a circular cross-section. The blood column diameter was measured from monochromatic $(575 \mathrm{~nm})$ retinal photographs using an instrument calibrated to produce readings in $\mu \mathrm{m}$ from a magnified retinal image. ${ }^{15}$

As previously described ${ }^{14}$ the uncertainty associated with individual measurements of the centreline blood velocity in retinal arteries is approximately plus or minus $20 \%$. The uncertainty associated with arterial diameter measurements is approximately plus or minus $2 \% .^{15}$

Data were analysed using the paired Student's $t$ test or correlation analysis. A p value of 0.05 or less was considered statistically significant.

\section{Results}

Table 2 shows the results of the laser Doppler measurements as well as the intraocular pressures measured in both eyes of the seven patients who had previously undergone uncomplicated 
Table 2 Intraocular pressure and laser Doppler measurements

\begin{tabular}{|c|c|c|c|c|c|c|c|c|c|c|c|c|}
\hline \multirow[b]{2}{*}{ Patient } & \multicolumn{3}{|c|}{ Intraocular pressure $(\mathrm{mm} \mathrm{Hg})$} & \multicolumn{3}{|c|}{ Diameter $(\mu m)$} & \multicolumn{3}{|c|}{$\begin{array}{l}\text { Centreline blood velocity } \\
(\mathrm{cm} / \mathrm{s})\end{array}$} & \multicolumn{3}{|c|}{ Blood flow rate $(\mu \mathrm{l} / \mathrm{min})$} \\
\hline & $T x$ & Fellow & $\%$ Diff & $T x$ & Fellow & $\%$ Diff & $T x$ & Fellow & $\%$ Diff & $\overline{T x}$ & Fellow & $\%$ Diff \\
\hline $\begin{array}{l}1 \\
2 \\
3 \\
4 \\
5 \\
6 \\
7 \\
\text { Mean (SD) }\end{array}$ & $\begin{array}{l}16 \\
15 \\
17 \\
13 \\
15 \\
11 \\
16\end{array}$ & $\begin{array}{l}19 \\
20 \\
18 \\
14 \\
21 \\
14 \\
19\end{array}$ & $\begin{array}{l}-16 \\
-25 \\
-6 \\
-7 \\
-29 \\
-21 \\
-16 \\
-17(9) \\
\mathrm{p}=0.004^{\star}\end{array}$ & $\begin{array}{r}118 \\
95 \\
119 \\
124 \\
106 \\
98 \\
111\end{array}$ & $\begin{array}{l}122 \\
129 \\
127 \\
113 \\
105 \\
104 \\
136\end{array}$ & $\begin{array}{c}-3 \\
-26 \\
-6 \\
10 \\
1 \\
-6 \\
-18 \\
-7(12) \\
\mathrm{ns}^{\star}\end{array}$ & $\begin{array}{l}3.5 \\
2.6 \\
3.7 \\
2.9 \\
2.8 \\
1.2 \\
2.5\end{array}$ & $\begin{array}{l}5 \cdot 2 \\
7 \cdot 3 \\
6 \cdot 7 \\
4 \cdot 0 \\
4 \cdot 5 \\
3 \cdot 3 \\
4 \cdot 4\end{array}$ & $\begin{array}{l}-33 \\
-64 \\
-45 \\
-27 \\
-38 \\
-64 \\
-43 \\
-45(14) \\
p=0.002^{\star}\end{array}$ & $\begin{array}{r}11.5 \\
5.5 \\
12.3 \\
10.5 \\
7.4 \\
2.7 \\
7.3\end{array}$ & $\begin{array}{r}18 \cdot 2 \\
28 \cdot 6 \\
25 \cdot 5 \\
12 \cdot 0 \\
11 \cdot 7 \\
8 \cdot 4 \\
19 \cdot 2\end{array}$ & $\begin{array}{l}-37 \\
-81 \\
-52 \\
-12 \\
-37 \\
-68 \\
-62 \\
-50(23) \\
p=0.01^{\star}\end{array}$ \\
\hline
\end{tabular}

$\star$ Comparison between treated and fellow eyes (2-tailed paired $t$ test).

$\mathrm{Tx}=$ surgically treated eye; Fellow =fellow eye; \% Diff =difference between treated and fellow eyes; $\mathrm{ns}=$ not significant.

unilateral scleral buckling procedures for rhegmatogenous retinal detachment (Table 1). In each case intraocular pressure was lower in the surgically-treated eye than in the fellow eye. The average percentage difference, 17 (SD 9)\% was statistically significant $(p=0 \cdot 004)$.

Laser Doppler measurements were obtained from a major superior or inferior temporal retinal artery in each surgically-treated eye and from the corresponding artery in the fellow eye. The retinal arteries were narrower in treated eyes in five of the seven patients but the average percentage difference, 7 (SD 12)\%, was not statistically significant. However centreline blood velocity was markedly lower in each treated eye artery than in the corresponding fellow eye artery. The average percentage difference, 45 (SD 14)\%, was statistically significant $(p=0.002)$. The pulsatility ratio, defined as the ratio of the centreline blood velocity measured at systole to that measured at diastole, was also computed for each artery. In each case this ratio was lower for arteries in treated eyes than in fellow eyes.

The arterial blood flow rate in each treated eye was lower than in the fellow eye due primarily to the marked differences in blood velocity rather than to the small differences in measured arterial diameter. The average percentage difference in blood flow rate, 50 (SD 23)\%, was statistically significant $(p=0.01)$.

Correlation analysis was used to determine if the results of the laser Doppler measurements were related to details of the prior surgery (duration and extent of the retinal detachment, elapsed time between surgery and measurements, extent of the implant, and presence or absence of fellow eye treatment) or to difference in mean blood pressure, heart rate, refractive error, or

Figure 1 Centreline blood velocity measured in retinal arteries of surgically treated eyes of patients who had unes of patients who had procedures plotted as $a$ function of the intraocular pressure. intraocular pressure. Only one significant correlation was found. As shown in Figure 1 there was a significant $(r=0.82, p=0.02)$ linear relationship between the centreline blood velocity and the intraocular pressure measured in surgically treated eyes. An interpretation of this finding is presented below.

Monochromatic retinal photographs of the two patients who were studied prior to and following surgical removal of scleral buckling elements are shown in Figures 2 and 3. The photographs shown were taken at the time of the laser Doppler measurements which followed removal of the buckling elements.

In the eye shown in Figure 2 prior to the removal of the intrascleral implant the diameter of the superotemporal artery at the laser Doppler measurement site was $126 \mu \mathrm{m}$, the centreline blood velocity was $2.9 \mathrm{~cm} / \mathrm{s}$, and the blood flow rate was $11 \mu \mathrm{l} / \mathrm{min}$. Following surgery the measured arterial diameter was $122 \mu \mathrm{m}$, the centreline blood velocity increased to $5.5 \mathrm{~cm} / \mathrm{s}$, and the blood flow rate increased by $73 \%$ to 19 $\mu \mathrm{l} / \mathrm{min}$.

In the eye shown in Figure 3 prior to the removal of a portion of the encircling band the diameter of the superotemporal artery at the laser Doppler measurement site was $117 \mu \mathrm{m}$, the centreline blood velocity was $2.6 \mathrm{~cm} / \mathrm{s}$, and the blood flow rate was $9 \mu \mathrm{l} / \mathrm{min}$. Following surgery the measured arterial diameter was $127 \mu \mathrm{m}$, the centreline blood velocity increased to $3.5 \mathrm{~cm} / \mathrm{s}$, and the blood flow rate increased by $44 \%$ to 13 $\mu \mathrm{l} / \mathrm{min}$.

In both of these patients the increases in arterial blood flow rate following surgery were due primarily to the increases in blood velocity.

\section{Discussion}

Our finding that the blood flow rates in retinal arteries of eyes that had undergone scleral buckling and encircling surgery were on average $50 \%$ lower than the flow rates measured in corresponding arteries in fellow eyes results from two factors: differences in vessel diameter and differences in blood speed. On average vessel diameters were $7 \%$ smaller in treated eyes than in fellow eyes. We have previously shown ${ }^{1+}$ that the blood speed varies as the square of the vessel diameter in the major branch retinal arteries of healthy volunteer subjects. Thus a $7 \%$ difference in vessel diameter would normally be accompanied by a $14 \%$ to $15 \%$ difference in blood speed. In the treated eyes however the 


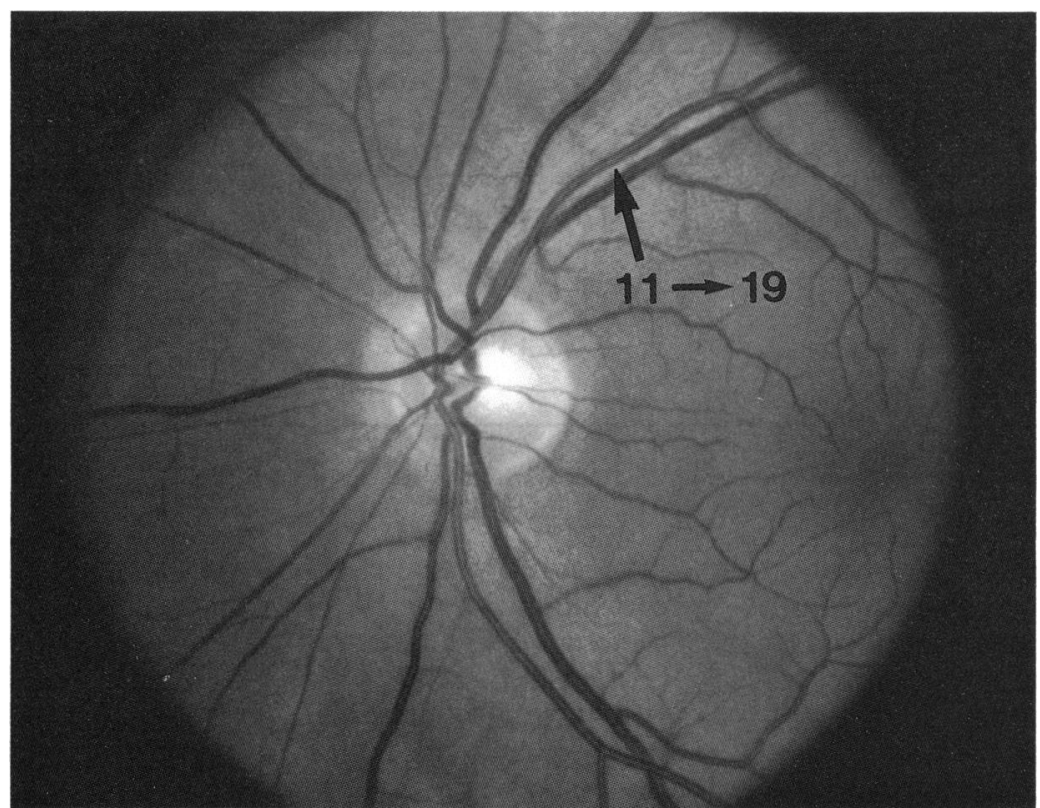

Figure 2 Photograph of the left eye of a patient taken after removal of an intrascleral implant. $B$ lood flow rates $(\mu \mathrm{l} / \mathrm{min})$ measured before and after surgery are shown. Large arrow indicates the measurement site.

blood speed was, on average, $45 \%$ lower than in fellow eyes. The measured difference in blood speed is thus much greater than would be expected due to differences in vessel diameter alone.

It is likely that the reduced blood speed is due to compressional mechanisms acting on the retinal vasculature. Ohkubo ${ }^{16}$ found signs of reduced retinal perfusion in regions of reattached retina which were indented following scleral buckling procedures. Compressional mechanisms have been cited as the cause of reduced choroidal blood flow following scleral buckling procedures. ${ }^{9-11}$ In the case of the choroidal circulation reduced blood flow was attributed to the direct obstruction of choroidal venous drainage. Clearly however there is no direct compression of the central retinal vein due to scleral buckling or encirclement. Compression

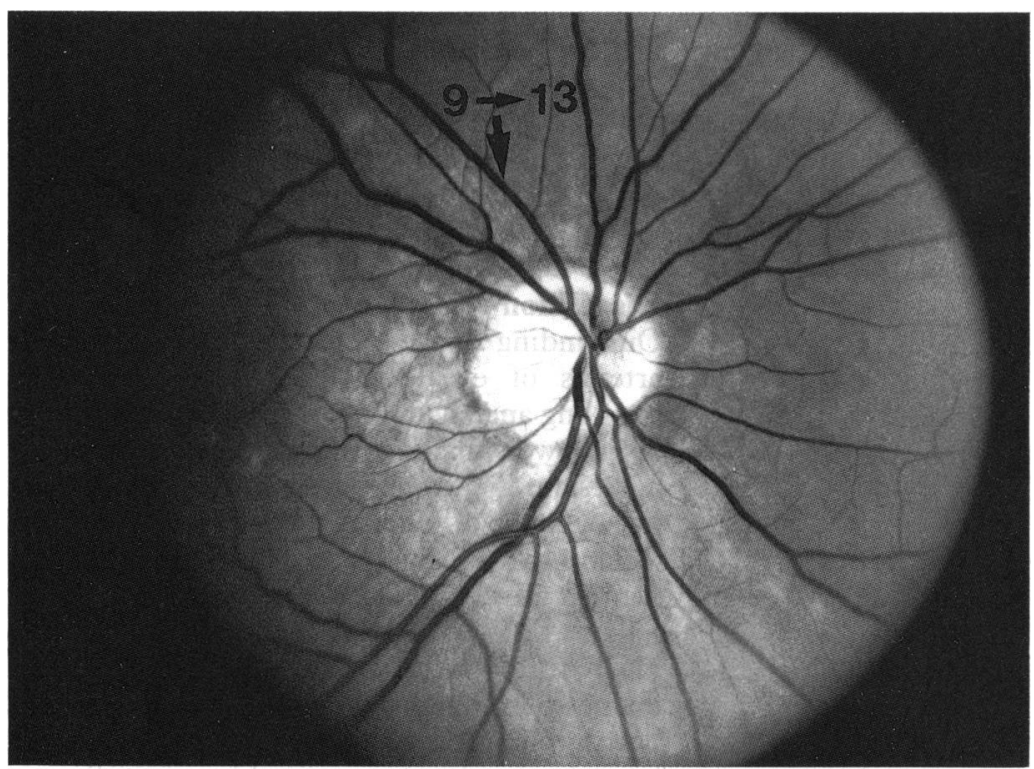

Figure 3 Photograph of the right eye of a patient taken after removal of a portion of an encircling band. Blood flow rates $(\mu \mathrm{l} / \mathrm{min})$ measured before and after surgery are shown. Large arrow indicates the measurement site. of the peripheral retinal circulation due to indentation is thus the likely cause of the reduced retinal blood flow rate.

Our finding of a significant positive correlation between retinal blood speed and intraocular pressure in treated eyes provides indirect evidence that there is a parallel reduction in retinal and choroidal perfusion following surgery. As described by Dobbie ${ }^{11}$ there is altered perfusion of the anterior choroid, ciliary body, and ciliary processes in patients with encircling bands. This altered perfusion results in a decreased ocular pulse amplitude, decreased aqueous humour formation and, as a result, a chronically decreased intraocular pressure. We also found that intraocular pressure was lower in surgically treated eyes than in fellow eyes. If we associate a lower intraocular pressure with a lower choroidal perfusion then our finding of a positive correlation between retinal blood speed and intraocular pressure suggests that the largest reductions in retinal blood speed occur when the choroidal perfusion is also most impaired.

Our finding of marked increases in retinal arterial blood flow following removal of scleral buckling elements in two patients confirms our previous report ${ }^{12}$ of a similar increase measured in a patient following removal of an intrascleral implant and an encircling band. As cited above Diddie and Ernest $^{10}$ found that removal of encircling bands in rabbit eyes returned the decreased choroidal blood flow to normal levels. Removal of buckling elements thus appears to affect both the choroidal and retinal circulations in a similar manner.

It should be stressed that even though retinal and choroidal blood flow decreases appear to be a common occurrence after scleral buckling procedures patients do not typically experience long term visual complications following successful surgery. In cases where there are complications it may be due to the fact that in those patients there is a greater susceptibility to the effects of reduced ocular blood flow.

This work was supported in part by USPH Grant EY01303 from the National Institute of Health and the Massachusetts Lions Eye Research Fund.

The authors wish to thank Douglas G Goger, BA for his assistance in analysing the data and for his helpful comments. We also thank Charles L Schepens, MD and Ronald C Pruett, MD for referring patients for this study.

1 Boniuk M, Zimmerman LE. Necrosis of uvea, sclera, and retina following operations for retinal detachment. Arch Ophthalmol 1961; 66: 318-26.

2 Robertson DM. Anterior segment ischemia after segmenta episcleral buckling and cryopexy. Am $\mathcal{F}$ Ophthalmol 1975; 79: 871-4.

3 Hayreh SS, Scott WE. Anterior segment ischemia followin retinal detachment surgery. Mod Probl Ophthalmol 1979; 20 : 148-53.

4 Cohen S, Kremer I, Yassur Y, Ben-Sira I. Peripheral retinal neovascularization and rubeosis iridis after a bilateral circular buckling operation. Ann Ophthalmol 1988; 20: 153-6.

5 Foulds WS, Reid H. Chisholm IA. Factors influencing visua recovery after retinal detachment surgery. Mod Probl Ophthalmol 1974; 12: 49-57.

6 Jarrett WH, Brockhurst RJ. Unexplained blindness and optic atrophy following retinal detachment surgery. Arch Ophthalmol 1965; 73: 782-91.

7 Hawkins WR, Schepens CL. Choroidal detachment and retinal surgery. A clinical and experimental study. $A m \mathcal{F}$ Ophthalmol 1966; 62: 813-14.

8 Packer AJ, Maggiano JM, Aaberg TM, Meredith TA, Reese FH, Kingham JD. Serous choroidal detartint FH, Kingham JD. Serous choroidal detachment after retin 9 Mano T. Choroidal circulation after encircling procedure. I. Immediate effect. Folia Ophthalmol fpn 1982; 33:460-7.

10 Diddie KR, Ernest JT. Uveal blood flow after $360^{\circ}$ : $460-7$. in the rabbit. Arch Ophthalmol 1980;98:729-30. 
11 Dobbie JG, Circulatory changes in the eye associated with retinal detachment and its repair. Trans Am Ophthalmol Soc 1980; 78: 503-66.

12 Yoshida A, Feke GT, Green GJ, et al. Retinal circulatory changes after scleral buckling procedures. Am $\mathcal{F}$ Ophthalmol

13 Feke GT, Goger DG, Tagawa H, Delori FC. Laser Doppler technique for absolute measurement of blood speed in retinal vessels. IEEE Trans Biomed Eng 1987; 34: 673-80. 14 Feke GT, Tagawa H, Deupree DM, Goger DG, Sebag J,
Weiter JJ. Blood flow in the normal human retina. Invest Ophthalmol Vis Sci 1989; 30: 58-65.

15 Delori FC, Fitch KA, Feke GT, Deupree DM, Weiter JJ. Evaluation of micrometric and microdensitometric method or measuring the width of retinal vessel images on fundus photographs. Graefes Arch Clin Exp Ophthalmol 1988; 226 : 393-9.

6 Ohkubo $H$. Fluorescein angiographic findings in the detatched and reattached retina. Fpn $\mathcal{F}$ Ophthalmol 1988; 32: 423-8. 